\title{
Nursing Care of the Patient Using Medical Marijuana
}

\section{Purpose of the Guidelines}

Over 31 US jurisdictions (including the District of Columbia), Guam, and Puerto Rico passed legislation legalizing cannabis for medical use. Several other jurisdictions also have legalized cannabis for medical use.* Each medical marijuana program has unique characteristics. In the United States, cannabis is a Schedule I Controlled Substance. Therefore, medical cannabis is unlike most other therapeutics in that providers cannot prescribe cannabis, nor can pharmacies dispense cannabis. However, applicable jurisdiction statutes and rules provide for the manufacture, distribution, and use of cannabis for medical purposes.

These guidelines provide nurses with principles of safe and knowledgeable practice to promote patient safety when caring for patients using medical marijuana.

\section{Definitions}

Cannabis. Any raw preparation of the leaves or flowers from the plant genus Cannabis. This report uses "cannabis" as a shorthand that also includes cannabinoids.

Cannabidiol ( $C B D)$. A major cannabinoid that indirectly antagonizes cannabinoid receptors, which may attenuate the psychoactive effects of tetrahydrocannabinol.

Cannabinoid. Any chemical compound that acts on cannabinoid receptors. These include endogenous and exogenous cannabinoids.

Cannabinol (CBN). A cannabinoid more commonly found in aged cannabis as a metabolite of other cannabinoids. It is nonpsychoactive.

Certify. The act of confirming that a patient has a qualifying condition. Many jurisdictions use alternative phrases such as "attest" or "authorize"; however, 13 of 29 jurisdictions use "certify" language in their statutes.

* In Australia, cannabis for medical use is federally legal, with states allowed to implement as they see fit. Although Bermuda has not legislated use of marijuana, their Supreme Court ruled that citizens could apply for personal licenses to possess cannabis for medical use. Cannabis for medical use is federally legal in all provinces of Canada. In New Zealand, physicians may prescribe CBD and cannabis-based products.
Clinical research. An activity that involves studies that experimentally assign randomized human participants to one or more drug interventions to evaluate the effects on health outcomes

Designated caregiver. An individual who is selected by the Medical Marijuana Program qualifying patient and authorized by the Medical Marijuana Program to purchase and/or administer cannabis on the patient's behalf. Also sometimes referred to as an "alternate caregiver."

Dronabinol. The generic name for synthetic tetrahydrocannabinol. It is the active ingredient in the U.S. Food \& Drug Administration-approved drug Marinol.

Endocannabinoid system. A system that consists of endocannabinoids, cannabinoid receptors, and the enzymes responsible for synthesis and degradation of endocannabinoids.

Marijuana. A cultivated cannabis plant, whether for recreational or medicinal use. The words "marijuana" and "cannabis" are often used interchangeably in various lay and scientific literature. These guidelines will primarily use the word "cannabis." When referring to a medical marijuana program, the guidelines will use the word "marijuana," as it is often used within program references.

Medical Marijuana Program (MMP). The official jurisdictional resource for the use of cannabis for medical purposes. Search the jurisdiction's website or Department of Health for "medical cannabis program" or "medical marijuana program."

Nabilone. The generic name for a synthetic cannabinoid similar to tetrahydrocannabinol. It is the active ingredient in the U.S. Food \& Drug Administration-approved drug Cesamet.

Schedule I Controlled Substance. Defined in the federal Controlled Substances $\mathrm{Act}^{2}$ as those substances that have a high potential for abuse; no currently accepted medical use in treatment in the United States; and a lack of accepted safety for use of the substance under medical supervision.

Tetrabydrocannabinol (THC). One of many cannabinoids found in cannabis. THC is the primary substance responsible for most of the characteristic psychoactive effects of cannabis. ${ }^{3}$ 


\section{Recommendations}

\section{Essential Knowledge}

1. The nurse shall have a working knowledge of the current state of legalization of medical and recreational cannabis use.

- The Drug Enforcement Agency (DEA) classifies cannabis as a Schedule I Controlled Substance. This classification not only probibits practitioners from prescribing cannabis, it also probibits most research using cannabis. ${ }^{4}$

- The process for obtaining cannabis for federally funded research purposes is cumbersome. Currently, the only legal source of cannabis for research purposes is grown in limited quantities at the University of Mississippi. ${ }^{5}$ The DEA sets an annual quota for cannabis grown for research purposes. ${ }^{6}$

- Over 31 jurisdictions (including the District of Columbia), Guam, and Puerto Rico passed legislation legalizing cannabis for medical purposes. In these laws, the jurisdiction has adopted exemptions legalizing the use of cannabis for medical purposes. Although the use of marijuana pursuant to authorized MMPs conflicts with federal law and regulations, at present there is no controlling case law bolding that Congress intended to preempt the field of regulation of cannabis use under its supremacy powers. ${ }^{7}$

- An increasing proportion of jurisdictions have also decriminalized or legalized recreational cannabis use. ${ }^{8}$

- The federal government's position on prosecuting the use of cannabis that is legal under applicable jurisdiction law has been set out in U.S. Department of Justice position papers. In 2009, the U.S. Attorney General took a position that discourages federal prosecutors from prosecuting people who distribute or use cannabis for medical purposes in compliance with applicable jurisdiction law; further similar guidance was given in 2011, 2013, and 2014. 9 In January 2018, the U.S. Office of the Attorney General rescinded the previous nationwide guidance specific to marijuana enforcement. The 2018 memorandum ${ }^{10}$ provides that federal prosecutors follow the well-established principles in deciding which cases to prosecute, namely, the prosecution is to weigh all relevant considerations, including priorities set by the attorneys general, seriousness of the crime, deterrent effect of criminal prosecution, and cumulative impact of particular crimes on the community.

2. The nurse shall have general knowledge of the principles of an MMP.

- MMPs are defined and described within the statute and rules of the specific jurisdiction. The relevant statute or rules are most easily located through the jurisdiction's Department of Health and $M M P .{ }^{11}$ Laws and rules regarding MMPs are an evolving process. Always confirm use of the most recent versions.

- A bealth care provider does not prescribe cannabis.

- The MMP will specify the qualifying conditions and the certifying process as well as the type of health care provider who can certify a qualifying condition. ${ }^{12}$

- The MMP will specify whether an advanced practice registered nurse can certify a qualifying condition and whether a specific course or training is required in order to participate in certifying an MMP qualifying condition. ${ }^{13}$

- After the qualifying condition is certified, the patient registers with the MMP. Once registered, the patient can obtain cannabis from a jurisdiction-authorized cannabis dispensary.

- Procurement and administration of cannabis for medical purposes are limited to the patient andlor the patient's designated caregiver. The MMPs will specify whether designated caregivers are permissible as well as the applicable process for registration as a designated caregiver. ${ }^{14}$

- In some jurisdictions, the MMP allows an employee of a hospice provider or nursing, or medical facility, or a visiting nurse, personal care attendant, or home health aide to act as a designated caregiver for the administration of medical marijuana. ${ }^{15}$

3. The nurse shall have a general understanding of the endocannabinoid system, cannabinoid receptors, cannabinoids, and the interactions between them.

- The endocannabinoid system consists of endocannabinoids, cannabinoid receptors, and the enzymes responsible for synthesis and degradation of endocannabinoids. ${ }^{16}$

- Discovered in 1973, this system includes a series of cannabinoid receptors throughout the body embedded in cell membranes that, when stimulated by endocannabinoids, are thought to promote homeostasis. ${ }^{17}$

- Endocannabinoids are naturally occurring substances within the body, while phytocannabinoids (plant substances that stimulate cannabinoid receptors) are found in cannabis. ${ }^{18}$

- The most well known of these cannabinoids is tetrahydrocannabinol (THC); bowever, cannabidiol (CBD) and cannabinol (CBN) are gaining interest in therapeutic use. ${ }^{19}$

4. The nurse shall have an understanding of cannabis pharmacology and the research associated with the medical use of cannabis.

Due to government restrictions on research involving cannabis, the surge of legislation has outpaced research, leaving nurses with few resources when caring for patients who use medical cannabis. Therefore, information regarding medicinal use of cannabis must be derived from moderate- to high-quality evidence using randomized placebo-controlled studies. These particular studies are the most likely to elucidate causality in treatments and are the only trusted source of evidence for cannabis as a clinical intervention. Research on cannabis is an evolving body of work. As with any scientific literature, it is important to rely on the most recent high-quality evidence.

a. Current scientific evidence exists for the use of cannabis for the following qualifying conditions

- Moderate- to high-quality evidence exists for

- cachexia

- chemotherapy-induced nausea and vomiting

- pain (resulting from cancer or rheumatoid arthritis)

- chronic pain (resulting from fibromyalgia),

- neuropatbies (resulting from HIV/AIDS, Multiple Sclerosis (MS), or diabetes) 
- spasticity (from MS or spinal cord injury). ${ }^{20}$

b. Adverse effects of cannabis use are influenced by the patient's condition and current medications

- The patient's propensity for the following may be exacerbated by cannabis: increased heart rate, increased appetite, sleepiness, dizziness, decreased blood pressure, dry mouth/dry eyes, decreased urination, ballucination, paranoia, anxiety, impaired attention, memory, and psychomotor performance. ${ }^{21}$

- Cannabis may exacerbate symptoms associated with asthma, bronchitis, and emphysema; cardiac disease; and alcobol or other drug dependence. ${ }^{22}$

- Cognitive impairment by cannabis may be dose- and age-dependent. ${ }^{23}$

- It is highly likely that cannabis will exacerbate symptoms of poor balance and posture in patients with dyskinetic disorders. Similarly, cannabis may worsen mental faculties in conditions that cause cognitive deficits. Patients who suffer from diseases with neurologic symptomology may show greater cognitive impairment. ${ }^{24}$

- Some participants report fatigue, suicidal ideation, nausea, asthenia, and vertigo as adverse effects of cannabis. ${ }^{25}$

- Cannabinoid receptors are effectively absent in the brainstem cardiorespiratory centers. This is believed to preclude the possibility of a fatal overdose from cannabinoid intake. ${ }^{26}$

- Cannabis can be a drug of abuse. Cannabis use disorder is defined as a problematic pattern of cannabis use leading to clinically significant impairment or distress; the clinical indications are included in the DSM-5. ${ }^{27}$

- Cannabis withdrawal syndrome has been identified as a syndrome seen in some patients whose cannabis use has been heavy and prolonged (i.e., usually daily or almost daily use over a period of at least a few months). The withdrawal syndrome has varying symptomatology, including insomnia, loss of appetite, physical symptoms, and restlessness initially, then irritability/ anger, vivid and unpleasant dreams after a week. ${ }^{28}$

c. Variable effects of cannabis are dependent on type of product and route of administration

- Since medical cannabis is not an FDA drug, there is no recommended dosage. Instead medical cannabis is titrated by the patient, with the principle of "start low, go slow."

- Continual patient assessment of perceived efficacy and adverse effects is recommended. Useful strategies include tracking dose, symptoms, relief, and adverse effects in a journal for review with the authorizing practitioner.

- FDA-approved synthetic THC drugs (dronabinol and nabilone) are administered orally or by an oromucosal route with a specific dosage.

d. Risks to particular groups of patients

- Adolescence. Many studies show a correlation between cannabis use and poor grades, high dropout rates, lower income, lower percentage of college degree completion, greater need for economic assistance, unemployment, and use of other drugs. Although these trends are related to recreational rather than medicinal cannabis use, the trends cannot be ignored but should be balanced with the benefits of cannabis for medical use. ${ }^{29}$

- Fertility. Two preclinical studies indicate that interference with endogenous cannabinoids might increase chances of failed embryo implantation ${ }^{30}$ and cannabinoids are capable of dysregulating bormones, which in turn can affect spermatogenesis. ${ }^{31}$

- Neonates. Presently there are no reliable data for neurodevelopmental outcomes with early exposure to cannabis in neonatal life, or through either breastfeeding or secondhand inhalation. 32,33,34

- Cannabis can be a drug of abuse and precautions should be taken to minimize the risk of misuse and abuse.

- Cannabis use may exacerbate existing psychoses in those with a risk of suicide or history of suicide attempt, schizophrenia, bipolar disorder, or other psychotic conditions. ${ }^{35}$

5. The nurse shall be aware of the facility or agency policies regarding administration of medical marijuana.

Always check with the facility and local Department of Health or MMP for more information on the facility policy when caring for a patient using cannabis medically. ${ }^{36}$

\section{Clinical Encounter Considerations}

1. As part of the clinical encounter for a patient using cannabis for medical use, the nurse shall conduct an assessment related to the following:

- Signs and symptoms of cannabis adverse effects

- Increased heart rate, increased appetite, sleepiness, dizziness, decreased blood pressure, dry mouth/dry eyes, decreased urination, hallucination, paranoia, anxiety, impaired attention, memory, psychomotor performance 37 as well a, symptoms associated with asthma, bronchitis, and emphysema ${ }^{38}$ or exacerbation of poor balance and posture in patients with dyskinetic disorders. 39

- Less frequently: fatigue, suicidal ideation, nausea, asthenia, and vertigo.

- Hyperemesis syndrome caused by overconsumption of edible cannabis product that can cause higher than normal blood concentrations of cannabinoids. 40

- Variable effects of cannabis are dependent on type of product and route of administration

- As medical cannabis dosage is titrated by the patient, with the principle of "start low, go slow," continual patient assessment of perceived efficacy and adverse effects is recommended.

- Useful strategies include tracking dose, symptoms, relief, and adverse effects in a journal.

2. The nurse shall communicate the findings of the clinical encounter to other health care providers and note such communication in documentation.

Clear, complete, and accurate documentation in a bealth record ensures that all those involved in a patient's care have access to information upon which to plan and evaluate their interventions. 
3. The nurse shall be able to identify the safety considerations for patient use of cannabis.

- Administration of cannabis for medical use can only be carried out by the certified patient or designated caregivers registered to care for the patient.

- Cannabis storage considerations include:

- keeping cannabis out of the reach of children, minors, and nonregistered individuals

- storing all cannabis products in a locked area

keeping cannabis in the original child-resistant packaging

- storing raw cannabis in a cool, dry, place

- following labeling guidelines for storage and expiration dates

- Disposal of unused cannabis products should be completed according to the DEA's Disposal Act. ${ }^{41}$ Generally, one can locate a collection receptacle via the DEA Registration Call Center (800-882-9539).

\section{Medical Marijuana Administration Considerations}

1. A nurse shall not administer cannabis to a patient unless specifically authorized by jurisdiction law. ${ }^{42}$

2. Instances in which the nurse may administer cannabis or synthetic THC to a patient.

- Administration of FDA-approved synthetic THC drugs (dronabinol and nabilone) as per facility formulary and policy

- As a registered MMP-designated caregiver

- The majority of jurisdictions allow a designated caregiver to assist a patient with the medical use of cannabis.

- These caregivers must meet specific qualifications and be registered with the MMP and must not practice outside of the limits of the caregiving statute. 43

- Some jurisdictions allow an employee of a hospice provider or nursing or medical facility, or a visiting nurse, to assist in the administration of medical marijuana.

- Check the most current MMP statute or rules. ${ }^{44}$

- Check facility policy regarding medical marijuana administration.

\section{Ethical Considerations}

In addition to ethical responsibilities under the nurse's jurisdictional law, the nurse shall approach the patient without judgment regarding the patient's choice of treatment or preferences in managing pain and other distressing symptoms.

Awareness of one's own beliefs and attitudes about any therapeutic intervention is vital, as nurses are expected to provide patient care without personal judgment of patients.

\section{References}

1 National Conference of State Legislatures (NCSL). (2017). State Medical Marijuana Laws. Retrieved from http://www.ncsl.org/ research/health/state-medical-marijuana-laws.aspx

2 Comprehensive Drug Abuse Prevention and Control Act. (1970). 21 U.S.C. $\S \$ 801-904$.
3 U.S. Department of Transportation. National Highway Traffic Safety Administration (NHTSA). (2107). Marijuana-Impaired Driving A Report to Congress. Retrieved from https://www.nhtsa.gov/ sites/nhtsa.dot.gov/files/documents/812440-marijuana-impaireddriving-report-to-congress.pdf

4 Comprehensive Drug Abuse Prevention and Control Act. (1970). 21 U.S.C. $\S \S 801-904$.

5 National Institute on Drug Abuse (NIDA). (May 2017). Information on Marijuana Farm Contract. Retrieved from https://www.drugabuse.gov/drugs-abuse/marijuana/

nidas-role-in-providing-marijuana-research/information-marijuanafarm-contract

6 U.S. Department of Justice, Drug Enforcement Administration (DEA). (November 8, 2017). Established Aggregate Production Quotas for Schedule I and II Controlled Substances and Assessment of Annual Needs for the List I Chemicals Ephedrine, Pseudoephedrine, and Phenylpropanolamine for 2018. 82 FR 51873. Retrieved from https://www.federalregister.gov/documents/2017/

11/08/2017-24306/established-aggregate-production-quotas-forschedule-i-and-ii-controlled-substances-and-assessment

7 Mikos. R.A. (December 12, 2012). On the Limits of Federal Supremacy: When States Relax (or Abandon) Marijuana Bans. Cato Institute. Policy Analysis, No. 714. Retrieved from https:/object. cato.org/sites/cato.org/files/pubs/pdf/PA714.pdf; Beek v. City of Wyoming. (February 6, 2014) (Findlaw, Dist. 145816). Retrieved from http://caselaw.findlaw.com/mi-supreme-court/1656759.html

8 NCSL. (2017). State Medical Marijuana Laws. Retrieved from http://www.ncsl.org/research/health/state-medical-marijuana-laws. aspx

9 U.S. Department of Justice, Office of Public Affairs (DOJ). (October 19, 2009). Attorney General Announces Formal Medical Marijuana Guidelines. Retrieved from https://www.justice.gov/opa/pr/attorney-general-announces-formal-medical-marijuana-guidelines; DOJ. (June 29, 2011). Guidance Regarding the Ogden Memo in Jurisdictions Seeking to Authorize Marijuana for Medical Use. Retrieved from https://www.justice.gov/sites/default/files/oip/legacy/2014/07/23/dag-guidance-2011-for-medical-marijuana-use.pdf; DOJ. (August 29, 2013). Guidance Regarding Marijuana Enforcement. Retrieved from https://www.justice.gov/iso/opa/resour ces/3052013829132756857467.pdf; DOJ. (February 14, 2013). Guidance Regarding Marijuana Related Financial Crimes. Retrieved from https://www.justice.gov/sites/default/files/usao-wdwa/legacy/2014/02/14/DAG\%20Memo\%20-\%20Guidance\%20Regarding $\% 20$ Marijuana\%20Related $\% 20$ Financial $\% 20$ Crimes $\% 202 \% 20$ 14\%2014\%20\%282\%29.pdf; DOJ. (October 28, 2014). Policy Statement Regarding Marijuana Issues in Indian Country. Retrieved from https://www.justice.gov/sites/default/files/tribal/pages/attachments/2014/12/11/policystatementregardingmarijuanaissuesinindiancountry2.pdf

10 DOJ. (January 4, 2018). Marijuana Enforcement. Retrieved from https://www.justice.gov/opa/press-release/file/1022196/download

11 NCSL. (2017). State Medical Marijuana Laws. Retrieved from http://www.ncsl.org/research/health/state-medical-marijuana-laws. aspx

12 Ibid.

13 Ibid.

14 Ibid.

15 Ibid.

16 Mackie K. Cannabinoid receptors: where they are and what they do. J Neuroendocrinol 2008; 20 Suppl 1: 10-4. http://onlinelibrary. wiley.com/doi/10.1111/j.1365-2826.2008.01671.x/full

17 Ibid.

18 Ibid. 
19 Pacher et al. The endocannabinoid system as an emerging target of pharmacotherapy. Pharmacological Reviews 2006; 58: 389-462. https://www.ncbi.nlm.nih.gov/pmc/articles/PMC2241751/

20 National Academies of Sciences, Engineering, and Medicine (National Academies of Sciences). (2017). The Health Effects of Cannabis and Cannabinoids: The Current Jurisdiction of Evidence and Recommendations for Research. Washington, D.C.: National Academy Press; Madras, B. (2015). Update of cannabis and its medical use. Retrieved from http://www.who.int/medicines/access/controlled-substances/6_2_cannabis_update.pdf

21 Federal Drug Administration. (September 2004). Marinol (Dronabinol) Capsules. Retrieved from https://www.fda.gov/ohrms/dockets/ dockets/05n0479/05N-0479-emc0004-04.pdf

22 Hall, W., \& Solowij, N. (1998). Adverse effects of cannabis. The Lancet, 352(9140), 1611-1616; Tashkin, D. P. (2013). Effects of marijuana smoking on the lung. Annals of the American Thoracic Society, 10(3), 239-247; Federal Drug Administration (FDA). (September 2004). Marinol (Dronabinol) Capsules. Retrieved from https://www.fda.gov/ohrms/dockets/dockets/05n0479/05N-0479emc0004-04.pdf

23 Crean, R. D., Crane, N. A., \& Mason, B. J. (2011). An evidence based review of acute and long-term effects of cannabis use on executive cognitive functions. Journal of addiction medicine, 5(1), 1; Solowij, N., \& Pesa, N. (2012). Cannabis and cognition: short and long-term effects. Marijuana and madness, 2, 91-102.

24 Koppel, B. S., Brust, J. C., Fife, T., Bronstein, J., Youssof, S., Gronseth, G., \& Gloss, D. (2014). Systematic review: Efficacy and safety of medical marijuana in selected neurologic disorders Report of the Guideline Development Subcommittee of the American Academy of Neurology. Neurology, 82(17), 1556-1563.

25 Collin, C., Ehler, E., Waberzinek, G., Alsindi, Z., Davies, P., Powell, K., ... \& Zapletalova, O. (2010). A double-blind, randomized, placebo-controlled, parallel-group study of Sativex, in subjects with symptoms of spasticity due to multiple sclerosis. Neurological research, 32(5), 451-459; National Academies of Sciences. (2017). The Health Effects of Cannabis and Cannabinoids: The Current Jurisdiction of Evidence and Recommendations for Research. Washington, D.C.: National Academy Press; Madras, B. (2015). Update of cannabis and its medical use. Retrieved from http://www.who.int/medicines/access/ controlled-substances/6_2_cannabis_update.pdf

26 Glass, M., Faull, R. L. M., \& Dragunow, M. (1997). Cannabinoid receptors in the human brain: a detailed anatomical and quantitative autoradiographic study in the fetal, neonatal and adult human brain. Neuroscience, 77(2), 299-318.

27 American Psychiatric Association. (2013). Diagnostic and statistical manual of mental disorders (5th ed.). Washington, DC: Author.

28 Hesse, M., \& Thylstrup, B. (2013). Time-course of the DSM-5 cannabis withdrawal symptoms in poly-substance abusers. BMC psychiatry, 13(1), 258; American Psychiatric Association. (2013). American Psychiatric Association. (2013). Diagnostic and statistical manual of mental disorders (5th ed.). Washington, DC: Author; Budney, A. J., Moore, B. A., Vandrey, R. G., \& Hughes, J. R. (2003). The time course and significance of cannabis withdrawal. Journal of abnormal psychology, 112(3), 393.

29 Madras, B. (2015). Update of cannabis and its medical use. Retrieved from http://www.who.int/medicines/access/controlledsubstances/6_2_cannabis_update.pdf; Crean, R. D., Crane, N. A., \& Mason, B. J. (2011). An evidence based review of acute and longterm effects of cannabis use on executive cognitive functions. Journal of addiction medicine, 5(1), 1.

30 Park, B., McPartland, J. M., \& Glass, M. (2004). Cannabis, cannabinoids and reproduction. Prostaglandins, leukotrienes and essential fatty acids, 70(2), 189-197.
31 du Plessis, S. S., Agarwal, A., \& Syriac, A. (2015). Marijuana, phytocannabinoids, the endocannabinoid system, and male fertility. Journal of assisted reproduction and genetics, 32(11), 1575-1588.

32 Jaques, S. C., Kingsbury, A., Henshcke, P., Chomchai, C., Clews, S., Falconer, J., ... \& Oei, J. L. (2014). Cannabis, the pregnant woman and her child: Weeding out the myths. Journal of Perinatology, 34(6), 417

33 Jutras-Aswad, D., DiNieri, J. A., Harkany, T., \& Hurd, Y. L. (2009). Neurobiological consequences of maternal cannabis on human fetal development and its neuropsychiatric outcome. European Archives of Psychiatry and Clinical Neuroscience, 259(7), 395-412.

34 Volkow, N. D., Baler, R. D., Compton, W. M., \& Weiss, S. R. (2014). Adverse health effects of marijuana use. New England Journal of Medicine, 370(23), 2219-2227.

35 Wilkinson, S. T., Radhakrishnan, R., \& D'Souza, D. C. (2014). Impact of cannabis use on the development of psychotic disorders. Current addiction reports, 1(2), 115-128.

36 NCSL. (2017). State Medical Marijuana Laws. Retrieved from http://www.ncsl.org/research/health/state-medical-marijuana-laws. aspx

37 FDA. (September 2004). Marinol (Dronabinol) Capsules. Retrieved from https://www.fda.gov/ohrms/dockets/dockets/05n0479/05N0479-emc0004-04.pdf

38 Hall, W., \& Solowij, N. (1998). Adverse effects of cannabis. The Lancet, 352(9140), 1611-1616; Tashkin, D. P. (2013). Effects of marijuana smoking on the lung. Annals of the American Thoracic Society, 10(3), 239-247

39 Koppel, B. S., Brust, J. C., Fife, T., Bronstein, J., Youssof, S., Gronseth, G., \& Gloss, D. (2014). Systematic review: Efficacy and safety of medical marijuana in selected neurologic disorders Report of the Guideline Development Subcommittee of the American Academy of Neurology. Neurology, 82(17), 1556-1563.

40 Calabria, B., Degenhardt, L., Hall, W., \& Lynskey, M. (2010). Does cannabis use increase the risk of death? Systematic review of epidemiological evidence on adverse effects of cannabis use. Drug and alcobol review, 29(3), 318-330.

41 DEA. (2014). Disposal Act: General Public Fact Sheet. Retrieved from https://www.deadiversion.usdoj.gov/drug_disposal/fact_sheets/ disposal_public.pdf

42 NCSL. (2017). State Medical Marijuana Laws. Retrieved from http://www.ncsl.org/research/health/state-medical-marijuana-laws. aspx

43 Ibid.

44 Ibid. 